\title{
INTEGRASI CHATBOT BERBASIS AIML PADA WEBSITE E-COMMERCE SEBAGAI VIRTUAL ASSISTANT DALAM PENCARIAN DAN PEMESANAN PRODUK (STUDI KASUS TOKO BUKU ONLINE EDU4INDO.COM)
}

\author{
Egga Bahartyan, Nurdin Bahtiar, dan Indra Waspada \\ Ilmu Komputer / Informatika FSM Universitas Diponegoro \\ eightghax@gmail.com,nurdinbahtiar@gmail.com,indrawaspada@gmail.com
}

\begin{abstract}
Abstrak
Perkembangan teknologi chatbot semakin canggih hingga saat ini. Mulai dari chatbot yang bernama ALICE, hingga aplikasi Siri milik perusahaan Apple sebagai virtual assistant yang berjalan pada iPhone masih dikembangkan agar semakin cerdas dan canggih untuk mempermudah pekerjaan manusia. Chatbot dapat diintegrasikan ke berbagai layanan, aplikasi atau sumber data lainnya. Salah satunya adalah mengintegrasikan chatbot dengan situs web e-commerce untuk menggantikan tugas manusia sebagai customer service. Salah satu caranya adalah memanfaatkan layanan AIML interpreter milik Pandorabots. AIML berfungsi sebagai "otak" pada chatbot, berisi basis pengetahuan yang dipersiapkan untuk menghasilkan jawaban. Pengembangan aplikasi chatbot dilakukan menggunakan metodologi Ripple yang merupakan kombinasi metodologi berorientasi objek dengan fase-fase klasik dari proses pengembangan perangkat lunak. Aplikasi yang dihasilkan diberi nama EIVA, chatbot yang berperan sebagai customer service pada toko buku online Edu4indo.com. Interaksi pelanggan dengan chatbot yang menggunakan bahasa alami diharapkan dapat menjadikan chatbot lebih memahami apa yang dimaksudkan pelanggan bila dibandingkan dengan penggunaan alat bantu pencarian tradisional dengan banyak pilihan atau bahkan textbox tunggal untuk memasukkan kata kuncinya.
\end{abstract}

Kata kunci : chatbot, bahasa alami, e-commerce, AIML, Pandorabots

\section{PENDAHULUAN}

Edu4indo adalah usaha jasa penyedia buku dan sarana pendidikan yang dikelola oleh praktisi pendidikan dan penyedia sarana pendidikan berpengalaman. Edu4indo memanfaatkan teknologi informasi dalam pemasaran produknya melalui sistem layanan elektronik. Salah satu pemanfaatan teknologi informasi pada Edu4indo yaitu situs web ecommerce dapat diakses melalui Edu4indo.com. Pelanggan dapat dengan mudah melakukan pencarian dan pemesanan produk milik Edu4indo melalui situs web e-commerce tersebut. Demi meningkatkan pelayanan kepada pelanggan, Edu4indo memiliki layanan customer service berupa media chatting dimana pelanggan dapat langsung bertanya menggunakan Yahoo! Messenger seputar Edu4indo dan produknya atau bahkan untuk melakukan pemesanan.

Namun, dari penjelasan di atas ternyata memiliki kendala. Pelanggan yang tidak sedang menggunakan atau belum memiliki akun Yahoo! Messenger tidak dapat menggunakan layanan customer service. Disamping itu, Edu4indo tidak menyediakan layanan customer service selama 24 jam per hari, yaitu hanya dapat digunakan pada saat jam kerja. Dari permasalahan tersebut, dapat disimpulkan bahwa penggunaan layanan customer service menggunakan Yahoo! Messenger dirasa masih kurang cukup untuk memenuhi kualitas pelayanan bagi pelanggan Edu4indo, sehingga dibutuhkan suatu solusi untuk mengatasi permasalahan tersebut. Dalam hal ini, solusi yang dimaksud adalah bagaimana Edu4indo dapat memberikan pelayanan lebih kepada pelanggannya melalui customer service tanpa melalui Yahoo! Messenger dan dapat berkerja selama 24 jam per hari.

Dalam perkembangan teknologi saat ini terdapat banyak penelitian yang yang memanfaatkan chatbot sebagai virtual assistant atau shop assistant [5] [10]. Chatbot itu sendiri merupakan sebuah program komputer yang mampu berinteraksi dengan penggunanya dengan menggunakan bahasa alami [14]. Saat ini mulai banyak chatbot berbasis AIML (Artificial Intelligence Markup Language) yang digunakan sebagai virtual assistant pada beberapa aplikasi 
virtual assistant seperti Voice Actions, Skyvi, Iris, dan Call Mom (Pandorabots.com). AIML sering digunakan sebagai basis pengetahuannya (knowledge base) [17].

Dari permasalahan yang telah dipaparkan sebelumnya, yaitu mengenai peningkatan layanan Edu4indo terhadap pelanggannya dan penjelasan tentang pemanfaatan chatbot, maka dilakukan penelitian mengenai pemanfaatkan chatbot sebagai virtual assistant untuk pelanggan Edu4indo. Untuk selanjutnya chatbot ini akan disebut dengan Edu4indo Interactive Virtual Assistant disingkat dengan EIVA..

\section{DASAR TEORI}

\section{Metodologi Pengembangan Perangkat Lunak Ripple}

Ripple merupakan metodologi berorientasi objek yang diperkenalkan oleh Mike O'Docherty pada bukunya yang berjudul Object-Oriented Analysis and Design Understanding System Development with UML 2.0. Ripple terlihat seperti versi berorientasi objek dari semua fase klasik pada model pengembangan perangkat lunak. Karena object oriented sangat terjangkau, pengembang dapat terlibat dalam semua fase, pelanggan dapat terlibat dalam tahap awal, yang membantu pengembang untuk melakukan pekerjaan mereka, dan manajer tidak disingkirkan dari dunia pengembang, sehingga komunikasi semakin terjalin. Tabel 1 berikut menjelaskan gambaran singkat dari metodologi Ripple mengenai artefak apa saja yang dihasilkan pada setiap fasenya. Fase-fase pada metodogi Ripple meliputi Genesis, Requirements, Analysis, Class Specifiation, Implemention, Testing, Deployment, dan Maintenance.

\section{Pengertian Chatbot}

Chatbot adalah karakter bahasa alami yang berkomunikasi dengan penggunanya, atau orangorang yang sedang chatting di messenger, web instan, email, usenet, forum web, atau bahkan melalui komunikasi suara seperti telepon. Chatbot juga kadang-kadang disebut chat robot, bot, chatterbot, botchatting, chatterbox, V-Host, $V$-People, agent, dan manusia virtual. Sebuah chatbot dapat dikaitkan dengan sebuah avatar, animasi yang juga dapat mencakup sintesis pidato sehingga chatbot mungkin muncul lebih hidup melalui animasi virtual reality dan suara. Sebuah chatbot juga dapat memiliki teknologi pengenalan suara, sehingga bot hanya melalui teks. Chatbot memiliki botmaster, yaitu orang di belakang layar yang bertanggung jawab untuk menciptakan kepribadian bot dan melepaskannya ke tempat umum melalui internet. Membuat bot lebih seperti menciptakan karakter untuk sebuah novel atau skenario daripada seperti menulis sebuah program komputer [24].

\section{Situs Pandorabots.com}

Pandorabots.com adalah situs web bebas berbasis open-source yang dapat digunakan untuk mengembangkan dan mempublikasikan chatbot di web. "Pandorabots adalah komunitas terbesar chatbot di internet". Sejak Februari 2012 layanan komunitas gratis Pandorabots adalah rumah bagi lebih dari 166.000 botmaster dan 201.000 chatbots dalam berbagai bahasa. Lebih dari 1,4 miliar interaksi percakapan terjadi antara klien dan Pandorabots, dan jumlah ini meningkat cepat (dapat dilihat di dekat bagian atas tengah halaman web Pandorabots). Pandorabots digunakan di seluruh web silahkan masukkan kata kunci "talk?botid=" (dan termasuk tanda kutip) ke dalam kotak pencarian google untuk perkiraan jumlah terbaru.

Pandorabots sedang dalam pembangunan konstan dan memiliki komunitas yang aktif yang sangat besar. Pandorabots mematuhi standar terbuka untuk penerbitan chatbot. Untuk Pandorabots sejauh mungkin sendiri telah dibangun dari perangkat lunak open source. Pandorabots menggunakan AIML sebagai bahasa markup konten pengetahuan [25]. Untuk menggunakan layanan Pandorabots, hal pertama yang perlu dilakukan adalah mengunjungi situs Pandorabots pada http://pandorabots.com dan melakukan pendaftaran untuk sebuah akun. Setelah pendaftaran selesai dilakukan, kemudian Pandorabots akan memberikan halaman kontrol termasuk halaman training yang berfungsi untuk mengelola basis pengetahuan pada bot [24].

Setelah dilakukan training pada bot sehingga bot tersebut memiliki pengetahuan, maka untuk memanfaatkan bot tersebut agar dapat digunakan pada aplikasi pada pihak ketiga yaitu dengan 
cara menggunakan Pandorabots APIyang diakses pada http://www.pandorabots.com/ pandora/talk-xml dengan memberikan tiga parameter melalui method POST atau GET, yaitu:

1) botid, merupakan identitas bot yang didapat setelah berhasil melakukan registrasi

2) input, yaitu teks yang diberikan kepada bot

3) custid, digunakan untuk merekam percakapan yang berbentuk teks unik sebagai identitas pengguna bot agar percakapan dapat tetap pada konteksnya [24]

\section{AIML dan Unit-unit AIML}

AIML (Artificial Intelligence Markup Language) adalah bahasa pelengkap XML yang memungkinkan user untuk meng-costumize suatu chatbot (memasukan knowledge ke dalam chatbot) atau bahkan merancang sendiri suatu chatbot dalam waktu singkat dengan menggunakan teknologi free software A.L.I.C.E.. AIML dikembangkan oleh komunitas Alicebot dan telah menjadi dasar dari Alicebot pertama, yakni A.L.I.C.E. Berikut adalah unit-unit terpenting dari AIML

1) $<$ aiml $>$

Merupakan tag yang menandai awal dan akhir suatu dokumen AIML

2) <category $>$

Merupakan tag yang menandai "unit pengetahuan"

3) <pattern>

Digunakan untuk menyimpan pola sederhana yang sekiranya cocok dengan apa yang diketikkan oleh seorang pengguna pada Alicebot. Dengan kata lain, pattern merupakan pertanyaan hasil masukan pengguna. Pattern dalam bahasa AIML sangatlah sederhana dan hanya terdiri dari abjad, angka, karakter spasi, serta simbol wildcard ', dan '*'

4) $<$ template $>$

Berisi respon atau jawaban Alicebot terhadap masukan penguna. Dalam bentuk paling sederhana, template hanya terdiri dari teks datar. Namun umumnya, template dapat ditransformasikan ke dalam program komputer yang dapat menyimpan data, membuka program lain, dan melakukan beberapa tugas lainnya.
Selain yang disebutkan di atas, terdapat 20 atau lebih tag tambahan yang umumnya ditemukan dalam file AIML. Aplikasi A.L.I.C.E. memiliki knowledge yang mencakup sekitar 41.000 kategori.

Terdapat 2 (dua) tipe konteks opsional dalam AIML, yakni "that" dan "topic". Tag <that> dalam AIML terletak didalam kategori dan bertugas untuk menyimpan jawaban terakhir chatbot. Hal ini penting apabila chatbot mengajukan pertanyaan pada user. Sedangkan tag <topic> terletak diluar kategori dan bertugas untuk menyatukan kelompok kategori. Sebagai catatan, apabila respon terakhir chatbot adalah berupa paragraf (lebih dari satu kalimat), nilai "that" akan di-set menjadi kalimat terakhir dalam paragraf tersebut. Umumnya aplikasi $<$ that $>$ digunakan dalam Yes/No Question.

\section{Prestashop}

Prestashop adalah suatu platform perbelanjaan toko online yang gratis dan opensource. Prestashop sudah digunakan lebih dari 125.000 toko online yang aktif pada lebih dari 180 negara di seluruh dunia. Software Prestashop ringan, cepat, dan sangat fleksibel (www.prestashop.com/en/faq). CMS ini cukup populer di dunia dan banyak yang menggunakannya. Untuk mengetahui bagaimana struktur basis data Prestashop yang nantinya akan diintegrasikan dengan EIVA, dapat diunduh melalui alamat http://doc.prestashop.com/download/attachments /9404440/pdw-1.5-20130605.pdf.

\section{ANALISIS DAN PERANCANGAN}

\section{Kebutuhan}

Edu4indo Interactive Virtual Assistant atau disingkat dengan EIVA, merupakan sebuah sistem berbasis chatbot yang berfungsi layaknya customer service dimana penggunanya berinteraksi melalui chatting. Pengguna yang dimaksud disini adalah siapapun yang menggunakan atau berinteraksi dengan EIVA. Selanjutnya disebut dengan customer. Customer meminta dan EIVA melayani layaknya customer service. Customer dapat mencari produk dengan kriteria yang diinginkannya melalui bertanya. Selain itu, customer dapat memesan produk yang diinginkannya termasuk pada saat proses 
checkout. Selain itu, EIVA dapat melayani konfirmasi pembayaran pada customer yang sudah melakukan proses pembayaran dan mampu memberikan informasi status pemesana customer. Semua kegiatan tersebut dilakukan oleh customer dan EIVA melalui percakapan dengan bahasa alami (melakukan percakapan menggunakan bahasa Indonesia).

Semua pesanan customer disimpan sehingga pihak perusahaan dapat mengetahui detail customer berupa produk apa saja yang sudah dipesan beserta alamat dan detail pembayaran yang mendukung dalam proses transaksi. Semua daftar pesanan tersebut dikelola oleh pegawai perusahaan dapat disebut juga dengan administrator. Administrator bertugas melakukan validasi pembayaran jika terdapat customer yang sudah melakukan proses pembayaran. Setelah melakukan proses pengecekan, administrator dapat mengubah status pesanannya, misalnya dari "Menunggu Validasi Administrator" ke "Lunas, Sedang Dikirim" atau status pesanan lainnya.

\section{Diagram Use case}

Use case diagram disusun berdasarkan daftar actor dan daftar use case dan disusun berdasarkan hubungan keduanya, use case diagram sistem dapat dilihat pada Gambar 1.

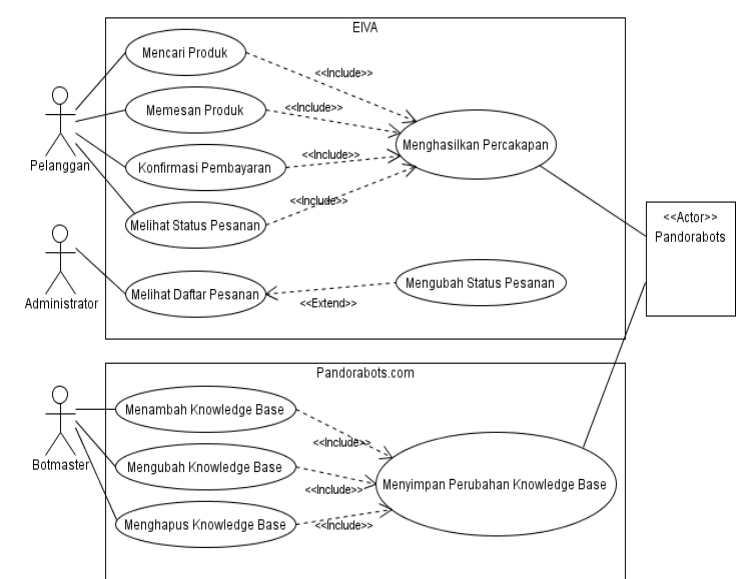

Gambar 1. Use Case Diagram Sistem

\section{Perancangan Antarmuka}

Sistem EIVA teridiri dari dua tampilan utama, yaitu EIVA untuk customer/pelanggan, dan untuk administrator. Aplikasi EIVA untuk customer merupakan aplikasi yang digunakan oleh customer dalam pencarian dan pemesanan produk. Oleh karena itu, kontrol utama yang ada dalam tampilannya terdiri dari:

1) Textbox, sebagai tempat untuk mengetikkan pertanyaan dari pelanggan

2) Response Box, digunakan untuk menghasilkan respon dari pertanyaan yang dikirim oleh pelanggan

3) Kotak Ekspresi, menghasilkan berbagai ekspresi yang berbeda sesuai dengan respon yang diberikan agar lebih interaktif Untuk lebih jelasnya, rancangan antarmuka EIVA untuk customer dapat dilihat pada gambar 2. Hanya terdapat satu bagian tampilan, tetapi pada bagian response box dapat berubah-ubah.

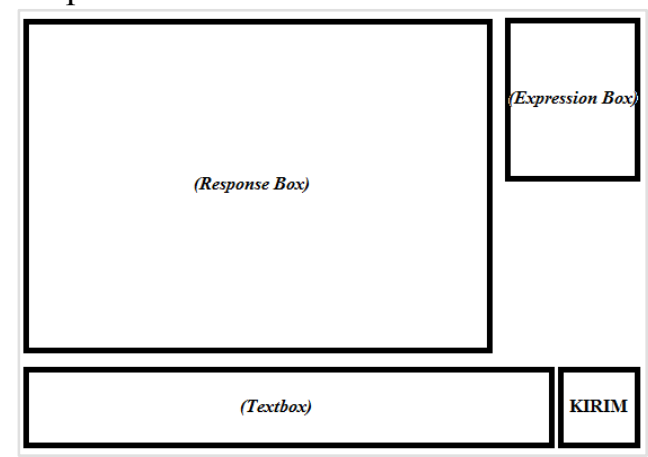

Gambar 2. Rancangan Antarmuka EIVA untuk Customer

Selanjutnya akan dijelaskan mengenai tampilan untuk administrator. Pada tugas akhir ini, sesuai judulnya mengenai integrasi situs web e-commerce dengan virtual assistant, maka tampilan administrator hanya dibuat dalam bentuk sederhana. Sehingga, komponen yang ditampilkan dalam antarmuka EIVA untuk administrator hanya berupa form untuk login dan tabel berisi daftar pesanan, dapat dilihat pada gambar 3 berikut.

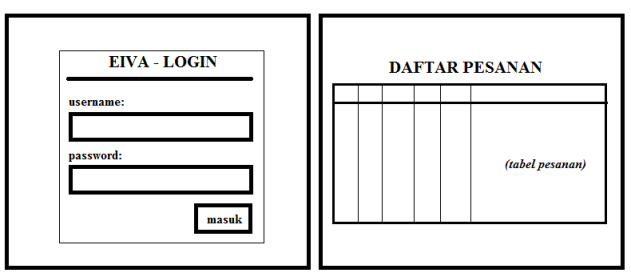

Gambar 3. Rancangan Antarmuka EIVA untuk Administrator

\section{Class Diagram Tahap Analisis}

EIVA merupakan kelas utama yang menggunakan fungsi dari kelas lain. EIVA 
menggunakan kelas Spellcheck untuk membetulkan kesalahan pengetikan yang dilakukan pengguna (pelanggan). Kemudian menggunakan kelas Pandorabots untuk mengambil teks jawaban polos yang terkadang berisi kata yang diberi tanda khusus. Kata tersebut merupakan nama fungsi untuk dipanggil dari kelas FunctionList berbagai fungsi yang juga terdapat fungsi yang menggunakan kelas lain, yaitu kelas Customer untuk mengelola data pelanggan, dan kelas Prestashop untuk menghubungkan dengan data produk bada basis data CMS Prestashop yang masih menggunakan kelas MySQLConnector. Kelas Customer memiliki atribut yang berkaitan, seperti produk, alamat pengiriman, daftar pesanan, keranjang belanja (cart) dan status pesanan. Kelas-kelas tersebut diberi nama Product, Order, Zone, Delivery, Carrier, OrderStatus, dan OrderCart dan saling berasosiasi. Hasil akhir proses dikemas pada kelas Response beserta masukan jawaban yang dibutuhkan berupa regular expression yang polanya sudah dipersiapkan pada kelas ResgexPatternlist. Gambar 4 berikut menunjukkan hasil class diagram tahap analisis.

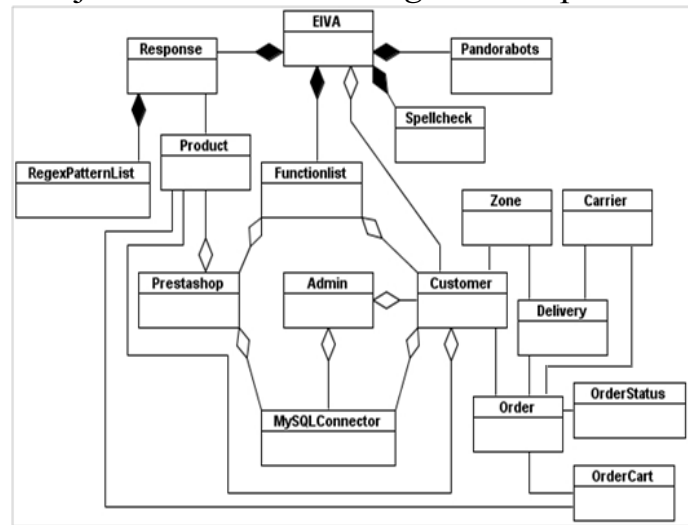

Gambar 4. Class Diagram Tahap Analisis

\section{Arsitektur Sistem}

Arsitektur sistem yang digunakan EIVA menggunakan konsep three-tier. Customer, administrator dan botmaster yang menggunakan browser untuk membuka halaman web berada pada client tier. Customer dan administrator terhubung dengan EIVA melalui internet. Customer dapat juga mencari dan memesan produk melalui halaman web Prestashop. Sedangkan botmaster mengelola AIML menggunakan Pandorabots control panel.
Aplikasi EIVA berjalan di dalam web server, begitu juga dengan CMS Prestashop. Komponen pemroses tersebut berada pada middle tier dan mengolah data yang terletak pada data tier. Perangkat pada data tier meliputi DBMS untuk menyimpan data produk dan pesanan. AIML interpreter menghasilkan respon berdasarkan file AIML pada server Pandorabots. Rancangan arsitektur sistem disajikan dalam bentuk deployment diagram pada gambar 5 berikut.

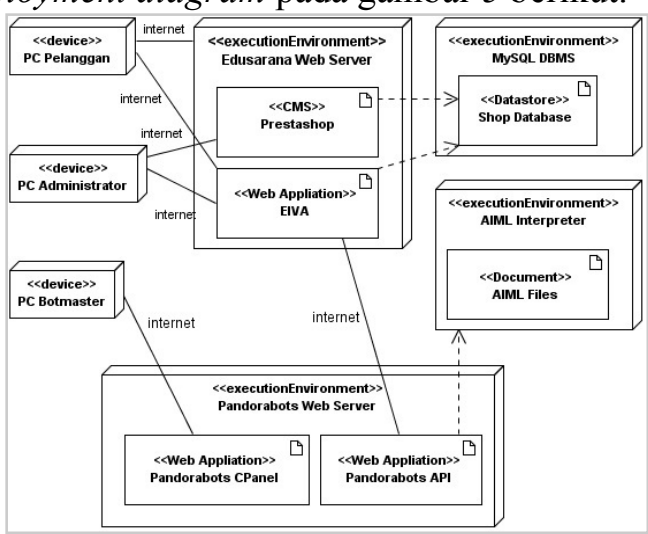

Gambar 5. Deployment Diagram Sistem EIVA

\section{Teknologi yang Digunakan}

EIVA merupakan sebuah sistem berbasis web sehingga teknologi yang digunakan merupakan komponen yang mendukung dalam pengembangan aplikasi web. Pada sisi client digunakan HTML dan javascript sebagai clientside scripting dan semakin dipermudah dalam proses pengembangannya dengan setelah menggunakan jQuery. Melalui browser yang digunakan customer, pengiriman data (yang berupa pertanyaan) dilakukan melalui AJAX sehingga halaman tidak perlu reload dalam proses percakapan antara customer dengan EIVA. Kemudian pertanyaan tersebut diproses pada sisi server menggunakan bahasa pemrograman yang mendukung server-side scripting, yaitu PHP. Bahasa pemrograman PHP memiliki fungsi yang dapat menghubungkan dan mengolah data menggunakan MySQL. PHP juga dapat digunakan untuk mengambil atau memanfaatkan web service, sehingga pertanyaan yang diberikan customer dapat diolah menggunakan PHP yang memanfaatkan Pandorabots API. 


\section{IMPLEMENTASI DAN PENGUJIAN}

\section{Penulisan Knowledge Base EIVA}

Knowledge Base digunakan agar EIVA dapat menjawab pertanyaan customer menggunakan bahasa alami. EIVA menggunakan AIML sebagai knowledge base. EIVA hanya memiliki pattern sebagai pertanyaan customer yang terbatas, segingga tidak semua pertanyaan yang diberikan customer dapat dimengerti. Jika EIVA menemui kondisi dimana pertanyaan yang diberikan customer tidak ada atau tidek dikenal oleh EIVA, maka secara default EIVA akan menjawab "Maaf, saya tidak mengerti maksud Anda". Syntax AIML yang berbentuk XML dikonversi menjadi tabel agar lebih mudah dibaca. Berikut merupakan daftar pertanyaan yang dikenal dan respon yang diberikan EIVA. Pada kode 1 berikut merupakan salah satu contoh category pada AIML yang digunakan EIVA.

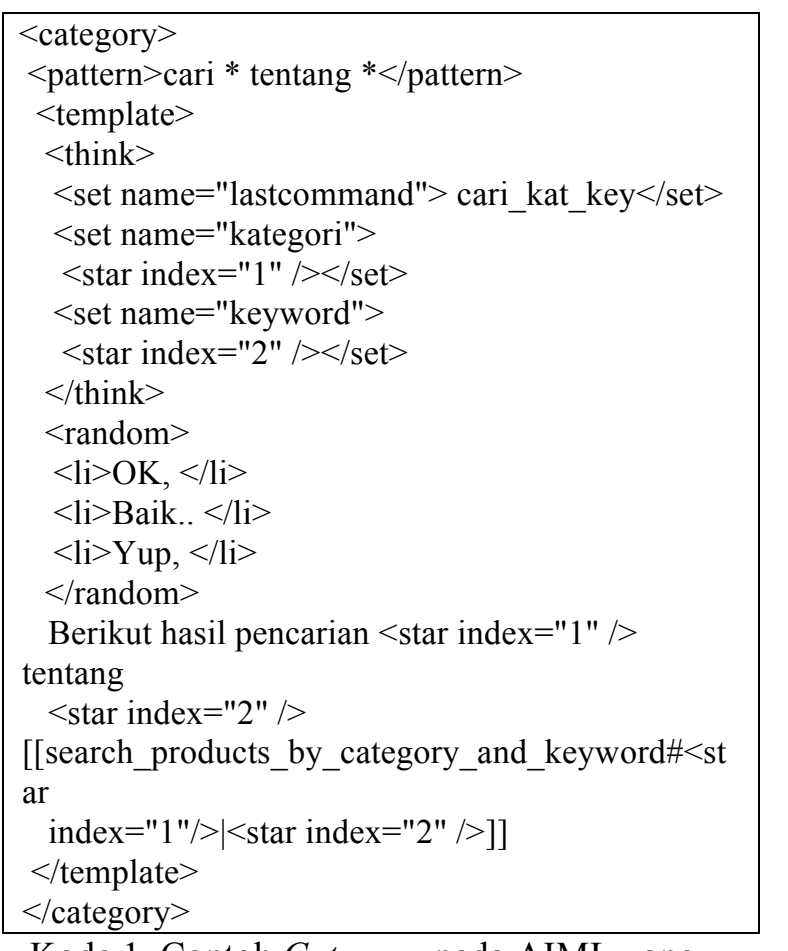

Kode 1. Contoh Category pada AIML yang Digunakan EIVA

Diantara tag pattern terdapat kalimat "cari * tentang *" yang berarti, EIVA dapat menerima pola dengan kata pertama "cari", kemudian diikuti kata atau kalimat apa saja sebelum kata "tentang" yang diikuti kata atau kalimat apa saja.
Misalnya "cari buku tentang binatang malam". Respon yang dihasilkan EIVA berada di dalam tag template selain pada tag think. Tag think mengeksekusi syntax yang ada di dalamnya, tetapi tidak dicetak. Tag set menyimpan kata atau kalimat yang dimasukkan ke dalam variabel dengan atribut name, sehingga variabel lastcommand berisi cari_kat_key, variabel kategori berisi kata pada pengganti tanda bintang (*) yang menggunakan tag star. Sehingga, sesuai contoh sebelumnya, variabel kategori berisi "buku" dan variabel keyword berisi "binatang malam". Tag random menghasilkan respon acak pada tag li. Setelah itu diikuti kalimat pengantar dan selanjutnya terdapat tanda "[[" diikuti nama fungsi yang sudah dipersiapkan. Diantara tanda "[[" dan"]]" terdapat tanda "\#" yang dibuat untuk membatasi antara fungsi dengan parameter. Sedangkan tanda "|" diguakan untuk membatasi parameter yang diberikan. Sehingga dalam kasus ini, Pandorabots akan memberikan jawaban seperti "Baik.. Berikut hasil pencarian buku tentang binatang malam [[search_products_by_category_and_keyword\#b uku|binatang malam]]" yang kemudian akan dilakukan parsing pada kelas EIVA berdasarkan hasil respon tersebut.

\section{Implementasi Antarmuka}

Gambar 6 berikut merupakan halaman awal EIVA. Saat pengguna (customer) membuka halaman EIVA, maka akan ditampilkan halaman dengan satu textbox untuk memasukkan kalimat pertanyaan, satu kotak diatasnya untuk menampilkan hasil jawaban, dan satu gambar wanita dengan berbagai ekspresi yang dapat berubah-ubah sebagai bentuk ekspresi.

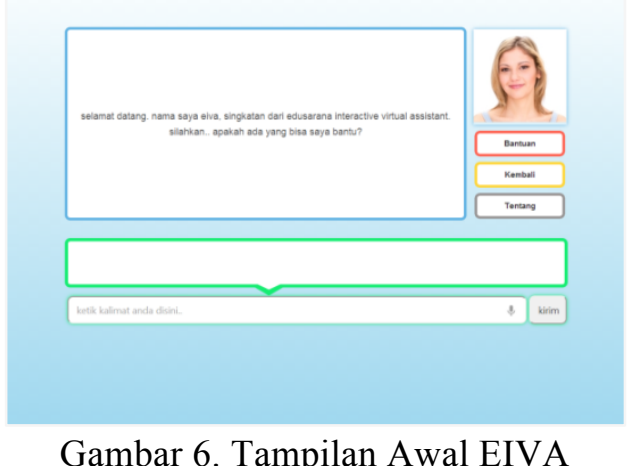

Gambar 6. Tampilan Awal EIVA 
Gambar 7 menunjukkan bagaimana interaksi EIVA dalam melayani pelanggan untuk pencarian produk. Sedangkan tampilan EIVA saat melayani pemesanan dapat dilihat pada gambar 8 .
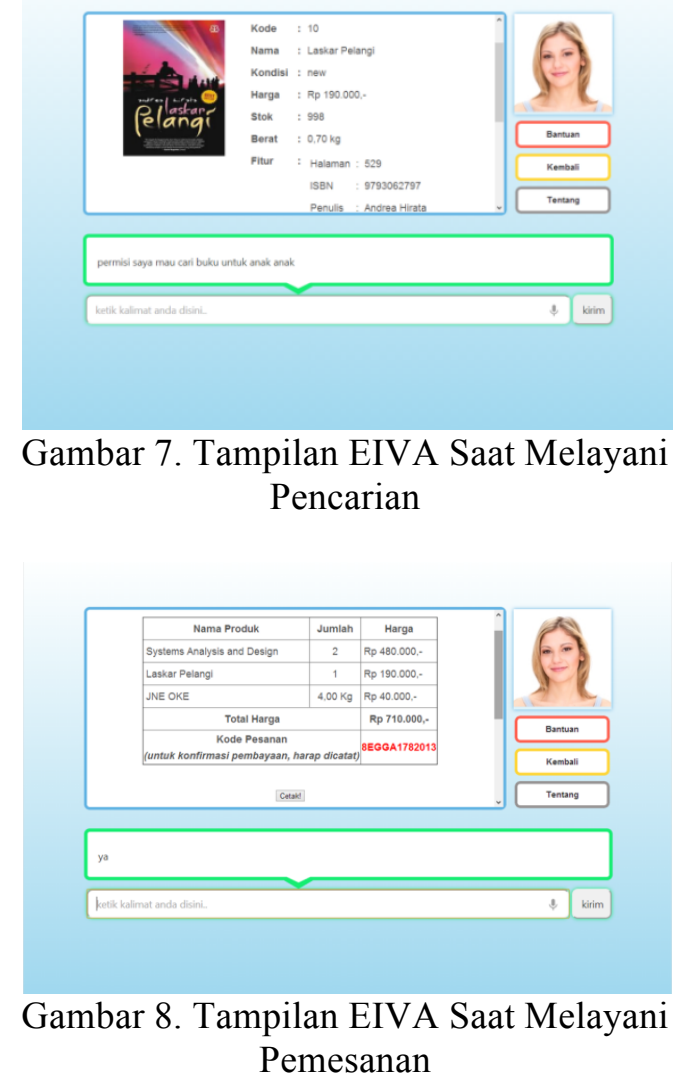

EIVA dapat memiliki berbagai ekspresi. Gambar 9 dan gambar 10 menunjukkan bagaimana EIVA memberikan respon saat berada pada kondisi-kondisi tertentu. Respon yang dihasilkan tidak hanya merubah kalimat, tetapi juga dapat menampilkan berbagai macam ekspresi wajah.

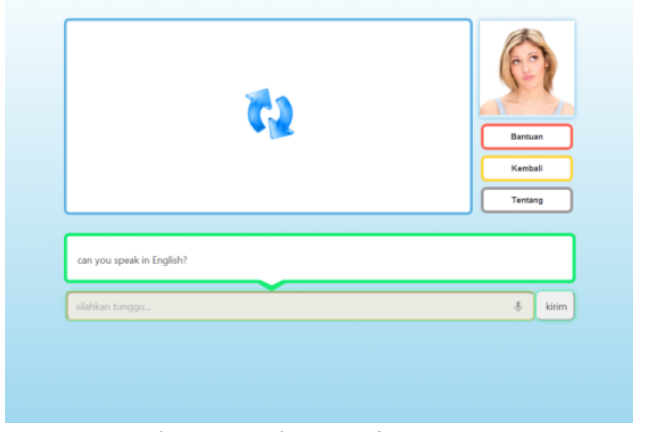

Gambar 9. Ekspresi EIVA Saat Proses

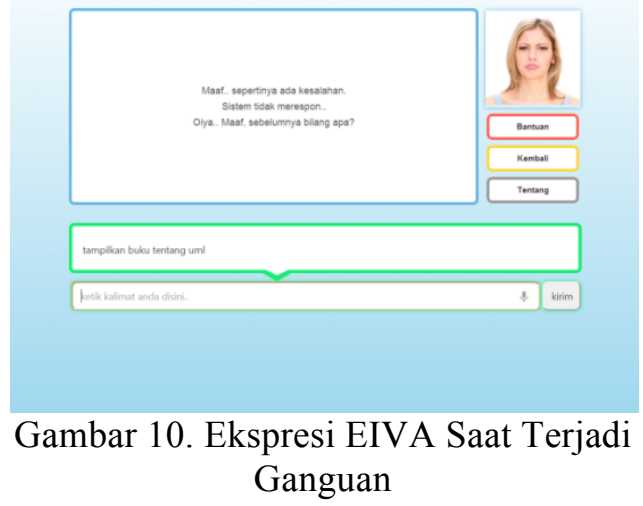

\section{Rencana Pengujian}

Terdapat 6 use case yang digunakan sebagai acuan pada tahap pengujian ini, yaitu Mencari Produk, Memesan Produk, Konfirmasi Pembayaran, Melihat Status Pesanan, Melihat Daftar Pesanan, dan Mengubah Status Pesanan. Rencana pengujian EIVA ditunjukkan pada tabel 1 berikut.

Tabel 1. Rencana Pengujian

\begin{tabular}{|c|c|c|c|c|}
\hline No & Use Case & Pengujian & $\begin{array}{l}\text { Jenis } \\
\text { Pengujian }\end{array}$ & $\begin{array}{l}\text { Identifikas } \\
\text { Pengujian }\end{array}$ \\
\hline \multirow[t]{2}{*}{1.} & \multirow[t]{2}{*}{ Mencari Produk } & $\begin{array}{l}\text { Mencari produk yang } \\
\text { ada pada basis data }\end{array}$ & blackbox & U-1-01 \\
\hline & & $\begin{array}{l}\text { Mencari produk yang } \\
\text { tidak ada pada basis } \\
\text { data }\end{array}$ & blackbox & U-1-02 \\
\hline \multirow[t]{2}{*}{2.} & \multirow[t]{2}{*}{ Memesan Produk } & $\begin{array}{l}\text { Memesan produk yan } \\
\text { ada pada basis data }\end{array}$ & blackbox & $\mathrm{U}-2-01$ \\
\hline & & $\begin{array}{l}\text { Memesan produk yang } \\
\text { tidak ada pada basis } \\
\text { data }\end{array}$ & blackbox & $\mathrm{U}-2-02$ \\
\hline \multirow[t]{2}{*}{3.} & \multirow[t]{2}{*}{$\begin{array}{l}\text { Konfirmasi } \\
\text { Pembayaran }\end{array}$} & $\begin{array}{l}\text { Menggunakan kode } \\
\text { pesanan yang terdaftar }\end{array}$ & blackbox & U-3-01 \\
\hline & & $\begin{array}{l}\text { Menggunakan kode } \\
\text { pesanan yang tidak } \\
\text { terdaftar }\end{array}$ & blackbox & $\mathrm{U}-3-02$ \\
\hline \multirow[t]{2}{*}{4.} & \multirow[t]{2}{*}{$\begin{array}{l}\text { Melihat Status } \\
\text { Pesanan }\end{array}$} & $\begin{array}{l}\text { Menggunakan kode } \\
\text { pesanan yang terdaftar }\end{array}$ & blackbox & U-4-01 \\
\hline & & $\begin{array}{l}\text { Menggunakan kode } \\
\text { pesanan yang tidak }\end{array}$ & blackbox & U-4-02 \\
\hline \multirow[t]{2}{*}{5.} & \multirow[t]{2}{*}{$\begin{array}{l}\text { Melihat Daftar } \\
\text { Pesanan }\end{array}$} & $\begin{array}{l}\text { Login menggunakan } \\
\text { usemame dan } \\
\text { password yang benar }\end{array}$ & blackbox & U-5-01 \\
\hline & & $\begin{array}{l}\text { Login menggunakan } \\
\text { usemame dan } \\
\text { password yang salah }\end{array}$ & blackbox & U-5-02 \\
\hline \multirow[t]{2}{*}{6.} & \multirow[t]{2}{*}{$\begin{array}{l}\text { Mengubah Status } \\
\text { Pesanan }\end{array}$} & $\begin{array}{l}\text { Memasukkan angka } \\
\text { pada kolom "Terbayar" } \\
\text { (masukkan valid } \\
\text { angka) }\end{array}$ & blackbox & $\mathrm{U}-6-01$ \\
\hline & & $\begin{array}{l}\text { Memasukkan huruf } \\
\text { pada kolom "Terbayar" } \\
\text { (masukkan valid } \\
\text { angka) }\end{array}$ & blackbox & U-6-02 \\
\hline
\end{tabular}




\section{Pelaksanaan Pengujian}

Pelaksanaan pengujian dilakukan dengan cara mengimplementasikan rencana pengujian yang telah disusun. Tabel 2 hingga tabel 7 berikut menunjukkan hasil pengujian yang telah dilakukan.

Tabel 2. Hasil Pengujian Pencarian Produk

\begin{tabular}{|c|c|c|}
\hline Identifikasi & U-1-01 & U-1-02 \\
\hline Deskripsi & $\begin{array}{l}\text { Mencari produk yang } \\
\text { ada pada basis data }\end{array}$ & $\begin{array}{l}\text { Mencari produk yang } \\
\text { tidak ada pada basis data }\end{array}$ \\
\hline $\begin{array}{l}\text { Prosedur } \\
\text { Pengujian }\end{array}$ & $\begin{array}{l}\text { Memasukkan pertanyaan } \\
\text { untuk mencari produk } \\
\text { yang ada pada basis data }\end{array}$ & $\begin{array}{l}\text { Memasukkan pertanyaan } \\
\text { untuk mencari produk } \\
\text { yang tidak ada pada } \\
\text { basis data }\end{array}$ \\
\hline Masukan & $\begin{array}{l}\text { Pertanyaan untuk } \\
\text { mencari produk yang ada } \\
\text { pada basis data, seperti } \\
\text { "tampilkan buku tentang } \\
\text { uml" }\end{array}$ & $\begin{array}{l}\text { Pertanyaan untuk } \\
\text { mencari produk yang } \\
\text { tidak ada pada basis data } \\
\text { "tampilkan buku tentang } \\
\text { zzzzzzzz" }\end{array}$ \\
\hline $\begin{array}{l}\text { Keluaran } \\
\text { yang } \\
\text { Diharapkan }\end{array}$ & $\begin{array}{l}\text { EIVA menampilkan } \\
\text { produk yang dicari }\end{array}$ & $\begin{array}{l}\text { Terdapat pemberitahuan } \\
\text { bahwa produk yang } \\
\text { dicari sedang kosong }\end{array}$ \\
\hline $\begin{array}{l}\text { Hasil yang } \\
\text { Didapat }\end{array}$ & $\begin{array}{l}\text { Produk yang dicari } \\
\text { ditampilkan }\end{array}$ & $\begin{array}{l}\text { EIVA menunjukkan } \\
\text { bahwa produk yang } \\
\text { dicari tidak ada / kosong }\end{array}$ \\
\hline Kesimpulan & Diterima & Diterima \\
\hline
\end{tabular}

Tabel 3. Hasil Pengujian Pemesanan Produk

\begin{tabular}{|l|l|l|}
\hline Identifikasi & \multicolumn{1}{|c|}{ U-2-01 } & \multicolumn{1}{c|}{ U-2-02 } \\
\hline Deskripsi & $\begin{array}{l}\text { Memesan produk } \\
\text { yang ada pada basis } \\
\text { data }\end{array}$ & $\begin{array}{l}\text { Memesan produk } \\
\text { yang tidak ada pada } \\
\text { basis data }\end{array}$ \\
\hline $\begin{array}{l}\text { Prosedur } \\
\text { Pengujian }\end{array}$ & $\begin{array}{l}\text { Memberikan kode } \\
\text { produk yang ada } \\
\text { pada basis data }\end{array}$ & $\begin{array}{l}\text { Memberikan kode } \\
\text { produk yang tidak } \\
\text { ada pada basis data }\end{array}$ \\
\hline Masukan & $\begin{array}{l}\text { Kode produk yang } \\
\text { ada pada basis data }\end{array}$ & $\begin{array}{l}\text { Kode produk yang } \\
\text { tidak ada pada basis } \\
\text { data }\end{array}$ \\
\hline $\begin{array}{l}\text { Keluaran } \\
\text { yang } \\
\text { Diharapkan }\end{array}$ & $\begin{array}{l}\text { Menuju ke proses } \\
\text { pemesanan } \\
\text { selanjutnya }\end{array}$ & $\begin{array}{l}\text { Memberikan } \\
\text { notifikasi bahwa } \\
\text { kode produk salah }\end{array}$ \\
\hline $\begin{array}{l}\text { Hasil yang } \\
\text { Didapat }\end{array}$ & $\begin{array}{l}\text { Menanyakan berapa } \\
\text { jumlah produk yang } \\
\text { ingin dipesan }\end{array}$ & $\begin{array}{l}\text { Memberikan } \\
\text { informasi bahwa } \\
\text { kode produk yang } \\
\text { diberikan salah dan } \\
\text { menawarkan untuk } \\
\text { kembali ke hasil } \\
\text { pencarian } \\
\text { sebelumnya }\end{array}$ \\
\hline Kesimpulan & Diterima & \begin{tabular}{l} 
Diterima \\
\hline
\end{tabular} \\
\hline
\end{tabular}

Tabel 4. Hasil Pengujian Konfirmasi

Pembayaran

\begin{tabular}{|l|l|l|}
\hline Identifikasi & \multicolumn{1}{|c|}{ U-3-01 } & \multicolumn{1}{c|}{ U-3-02 } \\
\hline Deskripsi & $\begin{array}{l}\text { Menggunakan kode } \\
\text { pesanan yang } \\
\text { terdaftar }\end{array}$ & $\begin{array}{l}\text { Menggunakan kode } \\
\text { pesanan yang tidak } \\
\text { terdaftar }\end{array}$ \\
\hline $\begin{array}{l}\text { Prosedur } \\
\text { Pengujian }\end{array}$ & $\begin{array}{l}\text { Memberikan kode } \\
\text { pesanan yang ada } \\
\text { pada basis data }\end{array}$ & $\begin{array}{l}\text { Memberikan kode } \\
\text { pesanan yang tidak } \\
\text { ada pada basis data }\end{array}$ \\
\hline Masukan & $\begin{array}{l}\text { Kode produk yang } \\
\text { ada pada basis data }\end{array}$ & $\begin{array}{l}\text { Kode produk yang } \\
\text { tdak ada pada } \\
\text { basis data }\end{array}$ \\
\hline $\begin{array}{l}\text { Keluaran } \\
\text { yang } \\
\text { Diharapkan }\end{array}$ & $\begin{array}{l}\text { Notifikasi bahwa } \\
\text { konfirmasi } \\
\text { pembayaran sudah } \\
\text { disimpan }\end{array}$ & $\begin{array}{l}\text { Notifikasi bahwa } \\
\text { kode pesanan tidak } \\
\text { terdaftar }\end{array}$ \\
\hline $\begin{array}{l}\text { Hasil yang } \\
\text { Didapat }\end{array}$ & $\begin{array}{l}\text { Notifikasi bahwa } \\
\text { konfirmasi } \\
\text { pembayaran sudah } \\
\text { disimpan }\end{array}$ & $\begin{array}{l}\text { Notifikasi bahwa } \\
\text { kode pesanan tidak } \\
\text { terdaftar }\end{array}$ \\
\hline Kesimpulan & Diterima & Diterima \\
\hline
\end{tabular}

Tabel 5. Hasil Pengujian Melihat Status Pembayaran

\begin{tabular}{|l|l|l|}
\hline Identifikasi & \multicolumn{1}{|c|}{ U-4-01 } & \multicolumn{1}{c|}{ U-4-02 } \\
\hline Deskripsi & $\begin{array}{l}\text { Menggunakan kode } \\
\text { pesanan yang } \\
\text { terdaftar }\end{array}$ & $\begin{array}{l}\text { Menggunakan kode } \\
\text { pesanan yang tidak } \\
\text { terdaftar }\end{array}$ \\
\hline $\begin{array}{l}\text { Prosedur } \\
\text { Pengujian }\end{array}$ & $\begin{array}{l}\text { Memasukkan kode } \\
\text { pesanan yang sudah } \\
\text { terdaftar }\end{array}$ & $\begin{array}{l}\text { Memasukkan kode } \\
\text { pesanan yang tidak } \\
\text { terdaftar }\end{array}$ \\
\hline Masukan & $\begin{array}{l}\text { Kode pesanan yang } \\
\text { sudah terdaftar }\end{array}$ & $\begin{array}{l}\text { Kode pesanan yang } \\
\text { tidak terdaftar }\end{array}$ \\
\hline $\begin{array}{l}\text { Keluaran } \\
\text { yang }\end{array}$ & $\begin{array}{l}\text { Informasi status } \\
\text { pesanan } \\
\text { berdasarkan kode } \\
\text { pesanan }\end{array}$ & $\begin{array}{l}\text { Notifikasi bahwa } \\
\text { kode pesanan yang } \\
\text { dimasukkan salah }\end{array}$ \\
\hline $\begin{array}{l}\text { Hasil yang } \\
\text { Didapat }\end{array}$ & $\begin{array}{l}\text { Informasi status } \\
\text { pesanan yang sesuai } \\
\text { dengan kode } \\
\text { pesanan }\end{array}$ & $\begin{array}{l}\text { Notifikasi bahwa } \\
\text { kode pesanan yang } \\
\text { dimasukkan salah }\end{array}$ \\
\hline Kesimpulan & Diterima & Diterima \\
\hline
\end{tabular}

Tabel 6. Hasil Pengujian Melihat Pesanan

\begin{tabular}{|l|l|l|}
\hline Identifikasi & \multicolumn{1}{|c|}{ U-5-01 } & \multicolumn{1}{c|}{ U-5-02 } \\
\hline Deskripsi & $\begin{array}{l}\text { Login menggunakan } \\
\text { username dan } \\
\text { password yang benar }\end{array}$ & $\begin{array}{l}\text { Login menggunakan } \\
\text { username dan } \\
\text { password yang salah }\end{array}$ \\
\hline $\begin{array}{l}\text { Prosedur } \\
\text { Pengujian }\end{array}$ & $\begin{array}{l}\text { Memasukkan } \\
\text { username dan } \\
\text { password yang benar }\end{array}$ & $\begin{array}{l}\text { Memasukkan } \\
\text { username dan } \\
\text { password yang salah }\end{array}$ \\
\hline Masukan & $\begin{array}{l}\text { Username dan } \\
\text { password yang benar }\end{array}$ & $\begin{array}{l}\text { Username dan } \\
\text { password yang salah }\end{array}$ \\
\hline $\begin{array}{l}\text { Keluaran } \\
\text { yang } \\
\text { Diharapkan }\end{array}$ & $\begin{array}{l}\text { Dialihkan ke } \\
\text { halaman yang berisi } \\
\text { daftar pesanan }\end{array}$ & $\begin{array}{l}\text { Diberi notifikasi } \\
\text { bahwa username } \\
\text { dan password salah }\end{array}$ \\
\hline $\begin{array}{l}\text { Hasil yang } \\
\text { Didapat }\end{array}$ & $\begin{array}{l}\text { Dialihkan ke } \\
\text { halaman yang berisi } \\
\text { daftar pesanan }\end{array}$ & $\begin{array}{l}\text { Diberi notifikasi } \\
\text { bahwa username } \\
\text { dan } \text { password salah }\end{array}$ \\
\hline Kesimpulan & Diterima & Diterima \\
\hline
\end{tabular}


Tabel 7. Mengubah Status Pesanan

\begin{tabular}{|c|c|c|}
\hline Identifikasi & U-6-01 & U-6-02 \\
\hline Deskripsi & $\begin{array}{l}\text { Memasukkan angka } \\
\text { pada kolom } \\
\text { "Terbayar" } \\
\text { (masukkan valid } \\
\text { angka) }\end{array}$ & $\begin{array}{l}\text { Memasukkan huruf } \\
\text { pada kolom } \\
\text { "Terbayar" } \\
\text { (masukkan valid } \\
\text { angka) }\end{array}$ \\
\hline $\begin{array}{l}\text { Prosedur } \\
\text { Pengujian }\end{array}$ & $\begin{array}{l}\text { Pada kolom } \\
\text { "Terbayar" dari } \\
\text { daftar pesanan } \\
\text { terdapat textbox, } \\
\text { kemudian } \\
\text { memasukkan angka } \\
\text { sebagai nominal } \\
\text { angka dari } \\
\text { pembayaran customer }\end{array}$ & $\begin{array}{l}\text { Pada kolom } \\
\text { "Terbayar" dari } \\
\text { daftar pesanan } \\
\text { terdapat textbox, } \\
\text { kemudian } \\
\text { memasukkan huruf } \\
\text { acak }\end{array}$ \\
\hline Masukan & Angka sembarang & Huruf sembarang \\
\hline $\begin{array}{l}\text { Keluaran yang } \\
\text { Diharapkan }\end{array}$ & $\begin{array}{l}\text { Data diperbarui, } \\
\text { jumlah kekurangan } \\
\text { pembayaran sesuai }\end{array}$ & $\begin{array}{l}\text { Terdapat notifikasi } \\
\text { yang menyatakan } \\
\text { bahwa data yang } \\
\text { dimasukkan salah }\end{array}$ \\
\hline $\begin{array}{l}\text { Hasil yang } \\
\text { Didapat }\end{array}$ & $\begin{array}{l}\text { Data diperbarui, } \\
\text { jumlah kekurangan } \\
\text { pembayaran sesuai }\end{array}$ & $\begin{array}{l}\text { Terdapat notifikasi } \\
\text { yang menyatakan } \\
\text { bahwa data yang } \\
\text { dimasukkan salah }\end{array}$ \\
\hline Kesimpulan & Diterima & Diterima \\
\hline
\end{tabular}

\section{Evaluasi Pengujian}

Berdasarkan hasil pengujian pada tabel 4.8 hingga 4.13 dapat dilihat bahwa pengujian yang telah dilakukan dapat diterima. Hasil yang didapat dari pelaksanaan pengujian menunjukkan kesesuaian dengan keluaran yang diharapkan. Adanya kesesuaian tersebut merupakan suatu bukti bahwa sistem berjalan sesuai dengan definisi kebutuhan. Sehingga, dalam hal ini dapat dinyatakan bahwa EIVA telah memenuhi syarat dan mampu untuk:

1) Mencari Produk

2) Memesan Produk

3) Konfirmasi Pembayaran

4) Melihat Status Pesanan

5) Melihat Daftar Pesanan

6) Mengubah Status Pesanan

\section{KESIMPULAN DAN SARAN}

\section{Kesimpulan}

Kesimpulan yang dapat diambil dalam pengerjaan tugas akhir ini adalah dihasilkannya sistem bernama Edu4indo Interactive Virtual Assistant (EIVA). Sistem ini dapat digunakan sebagai alternatif lain dalam pencarian dan pemesanan produk pada situs web e-commerce yang dalam kasus ini milik Edu4indo.com. EIVA berinteraksi dengan customer menggunakan bahasa Indonesia kemudian ditambah ekspresi yang bervariasi menjadikannya semakin interaktif sehingga dapat berfungsi layaknya customer service.

\subsection{Saran}

EIVA menggunakan AIML sebagai basis pengetahuannya. Semakin besar basis pengetahuannya, semakin banyak pertanyaan yang dikenalnya, maka akan semakin cerdas. Sehingga diharapkan botmaster dapat memperbanyak basis pengetahuan EIVA. Selain itu, diharapkan EIVA dapat menjadi sebuah modul Prestashop yang portable, customizable dan fleksibel, sehingga dapat digunakan di berbagai toko online.

\section{DAFTAR PUSTAKA}

[1] Allan, Dennis. 2009. "System Analysis and Design with UML". Hoboken: Wiley.

[2] Aloysius, SW. 2011. "Website Super Canggih dengan Plugin jQuery Terbaik". Jakarta Selatan: Mediakita.

[3] Ariesto, HS. 2001. "Analisis dan Desain Berorientasi Objek". Yogyakarta: J\&J Learing.

[4] Arulkumaran, Kumaraswamipillai. 2007. "Java/J2EE Job Interview Companion".: Lulu.com.

[5] Bayan, AS. 2007. "Chatbots: Are They Really Useful?": LDV-Forum.

[6] Bernd, Bruegge and Allen H, Dutoit, Eds. 2004. "Object Oriented Software Engineering Using UML, Pattern, and Java 2nd Edition". Munich: Pearson Education.

[7] Booch, G, et all. 2005. "The Unified Modelling Language User Guide 2nd Edition".: Pearson Education.

[8] C, Simon. 2012. "Advanced Web Technologies".: University of Westminster.

[9] Charles, MK. 2005. "The TCP/IP Guide: A Comprehensive, Illustrated Internet Protocols Reference".: No Starch Press.

[10] Eduardo, M. 2007. "Intelligent web navigation using virtual assistant". Granada: University of Granada.

[11] Frans. 2002. "Membuat Web Dinamis dan Interaktif dengan CGI". Yogyakarta: Penerbit Andi. 
[12] Ian, S. 2000. "Software Engineering 6th Edition". Jakarta: Erlangga.

[13] Joyce, C. 2002. "Natural Language Assistant: A Dialog System for Online Product Recommendation".: AI Magazine.

[14] Macrae, Callum. 2013. "Learning From Jquery". Sebastopol: O'Reilly.

[15] Martin, F. 2003. "UML Distilled: A Brief Guide to the Standard Object Modeling Language, Third Edition". Boston: Addison Wesley.

[16] Militiadis, DL and Naeve, Ambjorn, Eds. 2006. "Intelligent Learning Infrastructure for Knowledge Intensive Organizations: A Semantic Web Perspective".: Idea Group Inc.

[17] O'Docherty, Mike. 2005. "Object-Oriented Analysis and Design : Understanding System Development with UML 2.0". Chichester. England: John Wiley \& Sons Inc.

[18] Oracle, Corp. (2012) MySQL. [Online]. http://dev.mysql.com

[19] Peranginangi, Kasiman. 2006. "Aplikasi Web dengan PHP dan MySQL". Yogyakarta: Penerbit Andi.

[20] Rajib, M. 2009. "Fundamentals of Software Engineering 3rd Edition". New Delhi: PHI Learning Private Limited.

[21] Richardson, L and S, Ruby, Eds. 2007. "RESTful Web Services". Sebastopol: O'Reilly.
[22] S. Wallace, Richard. (2010, Dec.) Alicebot. [Online].

http://alicebot.blogspot.com/2010/12/integratin g-Pandorabots-with-third.html

[23] S. Wallace, Richard. 2005. "Be Your Own Botmaster".: ALICE A.I. Foundation.

[24] S. Wallace, Richard. (2010) Pandorabots. [Online].

http://www.pandorabots.com/botmaster/en/

[25] S. Wallace, Richard. 2009. "Parsing the Turing Test: Philosophical and Methodological Issues in the Quest for the Thinking Computer". The Anatomy of A.L.I.C.E. ed. Epstein, Robert, Roberts, Gary, and Beber, Grace, Eds. San Diego. United States of America: Springer.

[26] Samisa, A. 2008. "Restful PHP Web Services". Mumbai: PACKT Publishing.

[27] Schmuller, Joseph. 2004. "Sams Teach Yourself UML in 24 Hours". United States of America: Sams Publishing.

[28] Scott, W. Ambler. 2005. "The Elements of UML 2.0 Style". Cambridge: Cambridge University Press.

[29] Sylvia, $Q$, "A Chatbot-based Interactive Question Answering System," in Proceedings of The 11th Workshop on The Semantics and Pragmatics of Dialogue. Trento, 2007, vol. XI. 